\title{
LABORATORY STUDY ON SELF HEALING CONCRETE PAVEMENT - REVIEW PAPER
}

\author{
Prerana K, Rajrajeswari G, Ranjitha B R, S K Vidyashree \\ Department Of Civil Engineering \\ Dayananda Sagar College Of Engineering, Bangalore \\ Ranjitha $\mathrm{J}$ \\ Associate Professor \\ Department Of Civil Engineering \\ Dayananda Sagar College Of Engineering, Bangalore
}

\begin{abstract}
Concrete could be a variable material having several blessings. thus it's the foremost wide used material within the housing industry. several researchers created makes an attempt to use waste materials with the target of eliminating the disposal issues and at constant time up the properties of concrete.

Self-healing concrete is that the want of the hour within the current state of affairs. Deterioration is inevitable though innovations square measure streaming within the field of concrete technology. Admixtures return handy in economy purpose of read for achieving self healing in concrete structures thus on scale back the cracks within the earlier stage itself.

Self-healing technology could be a new field at intervals material technology. It represents a revolution in materials engineering and is dynamical the means that materials behave. Incorporating self healing technology into the road style method has the potential to rework building and maintenance processes by increasing the period of time of roads and eliminating the necessity for road maintenance.
\end{abstract}

Keywords: Pavement, self-healing, fiber reinforcement, fly ash, activated charcoal, compressive strength, preloading, crack healing, durability

\section{INTRODUCTION}

Conventional roads last for 5-10 years and need maintenance from time to time. thanks to significant rains and climatic conditions roads detoriate simply making cracks and potholes. Village roads can't be maintained properly. thence to extend the sturdiness of pavement of pavement self-healing technique came into follow.

Self-healing concrete could be a concrete with a capability to repair its own cracks and imperfections while not external designation or human intervention. Product period could be a crucial issue that ought to be maximized, particularly in road works whereas virtually everybody enjoys the gap of a brand new road that would save many minutes off their commute, and nobody likes to repair them. Roads square measure failing and government cannot sustain with the repairs. The roads would require less mating, increasing productivity whereas decreasing value.

Unlike the standard Rigid Pavement during which cement could be a key element, in self-repairing road it uses eightieth Cement a pair of and a couple of and a pair of $30 \%$ Fly-Ash And 2,3,4\% Activated Carbon. These materials on constituent with cement a

activated charcoal makes a standard grade concrete as High Strength and High Performance Concrete. the most content that self heals the road is fibers. The Fibers getting used in constructing self-repairing road, ought to have a synthetic resin and international organisation hydrous cement attracts water within the event of rains. The water then becomes a key element in healing cracks.

Fiber-reinforced concrete is good for up the sturdiness and toughness performance of concrete and mortar. Fibers in concrete facilitate scale back shrinkage cracks, increase strength, increase energy absorption and scale back dangerous spalling at high temperatures.

- polysaccharide Fibers: Manufactured from processed pulp merchandise, polysaccharide fibers square measure employed in an identical manner as micro-synthetic fibers for the management and mitigation of plastic shrinkage cracking.

- Glass Fibers: Glass fiber ferroconcrete (GFRC) has been preponderantly employed in fine arts applications and changed cement-based panel structures.

- Natural Fibers: Natural fibers square measure accustomed reinforce cement-based merchandise in noncommercial applications worldwide. They embody such materials as coconut, sisal, jute and sugarcane, and are available in variable lengths, geometries and material characteristics

- Steel Fibers: These fibers square measure typically used for providing concrete with increased toughness and post-crack load carrying capability. generally loose or 


\section{International Journal of Engineering Applied Sciences and Technology, 2021 \\ Vol. 5, Issue 10, ISSN No. 2455-2143, Pages 228-232 \\ Published Online February 2021 in IJEAST (http://www.ijeast.com)}

bundled, these fibers square measure typically made of carbon or stainless-steel, and square measure formed into variable geometries like crimped, hooked-end or wit different mechanical deformations for anchorage within the concrete.

- Fly ash: Flyash is employed as a supplementary building material material (SCM) within the production of hydraulic cement concrete. A supplementary building material material once employed in conjunction with hydraulic cement contribute to the properties of the hardened concrete. gift days construction industries wantquicker development and additionally need high strength of concrete to facilitate the quick and economic construction. This demand of high early strength grain of concrete place forth the utilization of low w/c magnitude relation.

- activated carbon: Activated carbon, additionally known as carbon, could be a kind of carbon processed to own little, low-volume pores that increase the extent. The Activated Carbon in the Concrete can increase the compressive strength obviously and scale back the pores in the rigid pavement

\section{OBJECTIVES}

- to check and lay high strength concrete road of activated charcoal, ash and fibre.

- to check compressive, Split tensile and flexural strength of concrete image created victimization ash and fibre.

- To asses the mechanical property of concrete and ash to check the sturdiness of concrete.

- Concrete is an adaptable material having many advantages. Therefore, it is the most widely used material in the construction industry. Many researchers made attempts to use waste materials with the objective of eliminating the disposal problems

\section{LITERATURE REVIEW}

Mustafa Şahmaran a, Victor C. Li b (2009) conducted a check to visualize the sturdiness properties of micro-cracked computer code containing high volumes ash. This paper presents the sturdiness of built building material Composites (ECC) that contain high percentages of Class-F ash (FA). computer code may be a new developed high performance fiber bolstered building material composite with substantial profit in each high malleability in more than threedimensional below uniaxial tensile loading and improved sturdiness because of as such tight crack dimension. Composites containing 2 totally different contents of solfa syllable as a replacement of cement (55 and seventieth by weight of total building material material) as examined when twenty eight days of natural process. Accelerated aging (exposure to continuous hydrated oxide at thirty eight ${ }^{\circ} \mathrm{C}$ and common salt solutions at area temperature) and tests of transport properties (salt ponding, speedy chloride permeableness and sorptivity tests) ar accustomed study the result of solfa syllable on the sturdiness of the computer code.

Takeshi Watanabe, Yuki Fujiwara (2011) performed the experiment to guage of self healing result in fly-ash concrete by supersonic check methodology. In experiment, ash replaced five and 15 August 1945 of unit sand content. to wreck ash concrete specimens, one among the state change and thawing check created by our laboratory were performed. when the check, the fly-ash concrete specimens ar cured by water and performed supersonic check. within the supersonic check, wave forms ar detected and wave rate and magnitude relation of relative dynamic modulus of physical property ar calculated. it's wide notable that wave rate injury|of injury|of harm $\} \mathrm{d}$ concrete is slower than sound concrete and dynamic modulus is employed for judge of damage. As a result, it's recognized that these fly-ash concrete specimens has self healing result. additionally, so as to research natural process result of concrete against state change and thawing injury, supersonic check methodology is powerful methodology of non harmful check.

Prof. Ing. Liberato FERRARA, Prof. Ing. Ravindra Gettu (2013), bestowed the paper on Self-Healing capability of Fiber bolstered Concretes with totally different Additions. during this work, the matter of self-healing of concrete are going to be investigated with relation to a traditional strength fiber ferroconcrete. The result of various widths of crack, exposure times to wet/dry cycles, application of a throughcrack compressive stress and also the ability of various additions to trigger the self healing ability of fabric are going to be thought of. a strategy for the assessment and quantification of mechanical recovery will be projected.

Khaled Z. Ramadana and Rami H. Haddadb (2015) bestowed the paper on the subject Self healing of overladen self compacting concrete of rigid pavement. this study aims at investigation the potential of self-healing and potential recovery of mechanical properties and sturdiness of SCC considering key parameters, stress level at loading, loading age, and natural process regime (water, air) and fundamental measure. For that, normal SCC cylinders $(150 \times 300 \mathrm{~mm})$ were solid from one SCC mixture, ready at a w/c magnitude relation of .45 , cured for various periods in water, then subjected to variable compressive stress levels starting from eighty to $100 \%$ of their final load capability, before re-cured in water or air for extra time periods, and eventually tested for supersonic pulse rate (UPV) and compressive mechanical response. 


\section{International Journal of Engineering Applied Sciences and Technology, 2021 \\ Vol. 5, Issue 10, ISSN No. 2455-2143, Pages 228-232 \\ Published Online February 2021 in IJEAST (http://www.ijeast.com)}

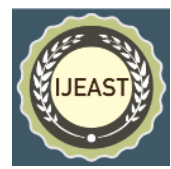

Amir Tabakovic' and Erik Schlangen(2015) bestowed a paper on the subject Self-Healing Technology for Asphalt Pavements. This paper explains the self-healing properties of asphalt pavement at the side of samples of self-healing technology for asphalt pavements like nano particles, warming, binder healing agent (rejuvenation). The paper conjointly talks concerning the advancement towards the new generations of self-healing asphalt pavements. The paper explains the price and environmental advantages of selfhealing technology for asphalt pavement style. it's explained that the crack repair in associate degree asphalt pavement system happens as a results of the wetting and lay diffusion of fabric between the 2 faces of a micro-crack, to regain the properties of the initial material. The 3 primary steps within the autonomous asphalt self-healing method ar wetting of the 2 faces of a micro-crack, diffusion of molecules from one face to the opposite and organisation of the subtle molecules to achieve the extent of strength of the initial material. The binder is that the key within the self-healing method. The healing of associate degree asphalt pavement at high temperatures is ruled by the thixotropic result, that describes the transformation of asphalt binder from a solid to gel state, permitting recovery from structural injury.

it's explained that the 5 essential conditions for self-healing agents to be enclosed into asphalt pavement style ar smart compatibility with hydrocarbon, heat stability, ability to survive combination and construction conditions, healing temperature between $30 \mathrm{C}$ and $40 \mathrm{C}$ and that they should be capable of continuous healing.

it's explained that to develop this new generation of selfhealing asphalt pavements, supported findings of presently obtainable self-healing technologies, 3 specific operating are known that require explicit effort that are development/design of injury sensing and repair triggering components, development of multiple self-healing processes and development of self-healing assessment mechanisms. The key objective of self-healing technology for asphalt pavement is that the development of a really sensible asphalt pavement system, capable of self-assessment and automatic response.

Despite the progress created within the development of selfhealing asphalt technology, additional work is needed to realize really sensible asphalt pavements. it's explained that the longer term work has to target injury sensing and repair triggering components, development of multiple self-healing processes and development of self-healing assessment mechanisms.

Amit Mittal, M B Kaisare ,Rajendra Kumar sethi (2017) bestowed a paper on AN Experimental Study on Use of ash in Concrete. during this paper to check the impact of partial replacement of cement by ash experiments are conducted on concrete mixes with $300-500 \mathrm{~kg} / \mathrm{cum}$ cementitous material at two hundredth, 30\%, 40\% and five hundredth replacement levels. during this paper the impact of flyash on workability, setting time, density, air content, compressive strength, modulus of physical property, shrinkage and porousness by fast chloride porousness check ar studied. supported the study , compressive study vs W/C curves are aforethought so the concrete mixes of grade M15 and M45 with totally different proportion of flyash will be directly designed. The experimental exercise have helped to check numerous|the varied|the assorted \} properties of flyash concrete and to develop combine|the combination|the combo $\}$ style curves for concrete mix proportioning with various proportion of flyash.

RA.B. Depaa1 and Dr. T.Felix Kala (2018), bestowed the paper on AN Experimental Study on Flyash as Self Healing Material. during this analysis work, ash (FA) is employed as AN admixture for achieving self-healing in concrete. totally different proportions ar tested and also the optimum replacement of ash is identified through an experiment as twenty fifth. Strength tests like compression, split tensile, flexure, unhearable pulse speed tests ar administrated to assess the mechanical properties of the concrete specimens. The specimens are cured for twenty eight days, preloaded for eightieth of final compressive strength and once more unbroken below continuous water exposure for one more twenty eight days therefore on facilitate self-healing method. The tests exclusive for crucial the self-healing method of concrete are sorptivity, water absorption, beam crack breadth and depth determination. FESEM and EDAX analysis are finished getting the crystal structure and mineral composition of the cured specimens. The check results indicated that ash well-tried to be a decent self-healing agent while not compromising on strength parameters.

Sai Dinakar Swaroop M, blue blood Arul rule G(2019) bestowed a paper on the subject Experiment on Concrete Containing with carbon and Nano-Fly ash, Nano Metakaolin. an endeavor has been created to enhance the compressive strength of concrete with carbon, Nano ash (NF) and Nano metakaolin (NM). during this work, the concrete combine was ready by commutation cement with twenty $\%(\mathrm{NF})$ and 100 percent (NM). Further, the concrete combine is another with zero. $4 \%, 0.8 \%, 1.2 \%, 1.6 \%, 1.8 \%$ and a couple of of carbon. The compressive strengths of cement were evaluated when 28days of solidification. it's ascertained that the concrete combine another with one. $2 \%$ of carbon exhibited the utmost strength. the utmost increase within the strength was found to be twenty fifth quite that of the concrete while not carbon

Roseline Dilani J.S., Santhosh L, Santhosh P, Santhosh S, Vaithiyanathan G (2020) bestowed a paper experimental study on self-repairing road. In therefore analysis work cement was replaced with two hundredth of flyash beside the addition of activated concrete and fiber reinforcement. These materials on constituent with cement and carbon makes a traditional grade concrete as High Strength and High Performance Concrete. the most content that self heals the 


\section{International Journal of Engineering Applied Sciences and Technology, 2021 \\ Vol. 5, Issue 10, ISSN No. 2455-2143, Pages 228-232 \\ Published Online February 2021 in IJEAST (http://www.ijeast.com)}

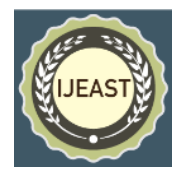

road is fibers. The Fibers being employed in constructing self repairing road, ought to have a epoxy glue and international organisation hydrous cement attracts water within the event of rains. The water then becomes a key part in healing cracks. once a crack seems, this water offers association capability to the unhydrated cement, and produces additional silicates, that truly shut the crack before they grow larger. Self repairing exploitation natural and artificial fibers coated with deliquescent nano coating that includes a impaired quality to repair the minute holes and hair pin line cracks which can be a breadth of regarding zero.01-2mm, and significantly it's like minded for street roads instead of country roads on increasing its sturdiness to double the span of typical road.

\section{METHODOLOGY}

The experiment is started with the gathering of raw materials that ar needed for the physical phenomenon of the experiment. The raw materials ar cement, fly ash, coarse combination, fine combination, carbon, fiber and water. to check the self-healing behaviour of concrete, cubes ought to be ready with varied proportion of ash and fiber reinforcement. in keeping with reference, a traditional M-45 concrete needs to be used.

Preliminary tests like sieve analysis, wet content check, sieve analysis check, etc ar conducted on the raw materials to grasp their physical and mechanical properties. Concrete cubes exploitation M-45 concrete ar casted with varied proportions of ash and fiber reinforcement.

After solidification for twenty eight days the cubes are tested for compressive strength, strength, flexural strength and unhearable pulse speed tests from 7-28 days to assess the mechanical properties of typical concrete. $70-80 \%$ of compressive strength applied to created small cracks. to establish the self-healing method the cubes ar cured for one more twenty eight days. when solidification, the strength tests ar conducted once more. each the check results ar compared, studied and analyzed. SEM analysis was administrated to grasp if the cracks are cured.

\section{CONCLUSIONS}

This project chiefly interests the look of rigid pavement as demand for road maintenance will increase road contractors and route engineers got to look wide for methods to enhance and maintain the roads. therefore we have a tendency to herewith concludes that roads with self healing property reduces the price of maintenance and it believes that with bound natural and artificial fibres we have a tendency to might done it. On the opposite hand these roads are arranged with high strength concrete containing carbon as a main strength up agent.

Self-healing properties ar comparatively unaccustomed material science. If a pavement will heal itself, it doesn't need commutation. Product time period may be a key issue that ought to be augmented, particularly in road works. Adding fibers, flyash, carbon in road pavement construction can increase the generation of the road and sturdiness compared to traditional asphalt and cement roads.

\section{Acknowledgement}

The writer desires to acknowledge the contribution of authors of the papers referred during this review and for his or her impact within the former's analysis

\section{REFERENCES}

1. Mustafa Şahmaran a, Victor C. Li(2009).” Durability properties of micro-cracked ECC containing high volumes fly ash". Department of Civil Engineering, Gaziantep University, 27310, Gaziantep, Turkey

2. Takeshi Watanabe, Yuki Fujiwara* , Chikanori Hashimoto† and Keisuke Ishimaru(2011)." EVALUATION OF SELF HEALING EFFECT IN FLY-ASH

CONCRETE BY ULTRASONIC TEST METHOD". International Journal of Modern Physics B Vol. 25, No. 31 (2011) 4307-4310

3. Relatore: Prof. Ing. Liberato FERRARACoRelatore: Prof. Ing. Ravindra GETTU(2015)." SelfHealing Capacity of Fiber Reinforced Concretes with Different Additions". POLITECNICO DI MILANO

4. Khaled Z. Ramadana and Rami H. Haddadb(2015)." Self-healing of overloaded selfcompacting concrete of rigid pavement". Article in European Journal of Environmental and Civil Engineering - September 2015

5. Amir Tabakovic and Erik Schlangen(2015). SelfHealing Technology for Asphalt Pavements . Materials and Environment, Faculty of Civil Engineering and Geosciences, Delft University of Technology, Delft, The Netherlands

6. Khushal Chandra Kesharwani, Amit Kumar Biswas1, Anesh Chaurasiya1, Ahsan Rabbani,(2019) ",Experimental Study on Use of Fly Ash in Concrete", International Research Journal of Engineering and Technology (IRJET)

7. RA.B. Depaa1 and Dr. T.Felix Kala(2018)"An Experimental Study on Flyash as Self Healing Material ",International Journal of Applied Engineering Research ISSN 0973-4562 Volume 13, Number 8 (2018) pp. 5920-5925 
Published Online February 2021 in IJEAST (http://www.ijeast.com)

8. Sai Dinakar Swaroop M, Prince Arul Raj G (2019),Experiment on Concrete Containing with Activated Carbon and Nano-Fly ash, Nano Metakaolin ,International Journal of Innovative Technology and Exploring Engineering (IJITEE)ISSN: 2278-3075, Volume8, Issue- 6S4,

9. Roseline Dilani J S, Santhosh L, Santhosh P, SanthoshSmr.G.Vaithiyanathan(2020)."EXPERIME NTAL STUDY ON SELF-REPAIRING ROAD". International Research Journal of Engineering and Technology (IRJET) Volume 7.
10. Mohd Nasim , U.K. Dewangan, Shirish V. Deo (2020)." Effect of crystalline admixture, fly ash, and PVA fiber on self-healing capacity of concrete" . Department of CivilEngineering, National Institute of Technology, Raipur, 